\title{
UMA INTRODUÇÃO À CIÊNCIA INDÍGENA E SUAS LEIS NATURAIS DE INTERDEPENDÊNCIA
}

\section{AN INTRODUCTION TO NATIVE SCIENCE AND ITS NATURAL LAWS OF INTERDEPENDENCE}

\section{CAJETE, GREGORY. NATIVE SCIENCE: NATURAL LAWS OF}

INTERDEPENDENCE. SANTA FE, NM: CLEAR LIGHT, 2000. P. 2-9.

Gregory Cajete

Tradução: Charles Bicalho*

Gregory Cajete é indígena do pueblo de Santa Clara, localizado no estado do Novo México, Estados Unidos. É professor na Universidade do Novo México (UNM), em Albuquerque. É diretor do departamento de Native American Studies e professor associado na Division of Language, Literacy and Socio Cultural Studies do College of Education da UNM. É autor dos livros Look to the Mountain: An Ecology of Indigenous Education (Kivaki Press, 1994); A People's Ecology: Exploration in Sustainable Living (Clear Light, 1999); Ignite the Sparkle: An Indigenous Science Education Curriculum Model (Kivaki Press, 1999); Native Science: Natural Laws of Interdependence (Clear Light, 2000); e Spirit of the Game: Indigenous Wellsprings (Kivaki Press, 2005).

Na introdução do livro Native Science: Natural Laws of Interdependence (Ciência indígena: leis naturais de interdependência),
* charlesbicalho@gmail.com

Pós-doutor em Mídia e Estudos Literários. Professor da Escola de Design da Universidade do Estado de Minas Gerais.

Cajete introduz o leitor numa tradição milenar de entendimento, experimentação e sentimento do mundo natural. Ele explora e registra a visão indígena da realidade, atravessando a arte, o mito, os rituais e os símbolos, bem como as práticas da ciência indígena. Cajete examina os múltiplos níveis de significado que informam a astronomia, a cosmologia, a psicologia, a agricultura e a cura indígenas. Diferentemente do método científico ocidental, o pensamento indígena não isola o objeto ou fenômeno para entendê-lo e interagir com ele, mas o percebe em termos de relações que o ligam às forças naturais e a todas as formas de vida. Tal método tem sido fundamental para os povos indígenas viverem harmonia espiritual e física com a terra por milênios. 
Nas línguas indígenas não há palavra para "ciência”, nem para "filosofia", "psicologia" ou qualquer outro modo fundamental de vir a conhecer e compreender a natureza da vida e nossas relações dentro dela. Não ter - ou, mais exatamente, não precisar de - palavras para ciência, arte ou psicologia não diminui sua importância na vida nativa. Para os povos nativos, a busca pela vida era a tarefa mais importante. Enquanto havia especialistas tribais com conhecimento particular sobre tecnologias e rituais, cada membro da tribo, em sua capacidade própria, era um cientista, um artista, um contador de história e um participante da grande teia da vida.

Ciência indígena, ou nativa, é uma metáfora para uma ampla variedade de processos tribais de percepção, pensamento, ação e o "vir a conhecer" que evoluíram através da experiência humana em contato com o mundo natural. A ciência nativa nasceu de uma participação vívida e histórica com a paisagem natural. Para se ter uma ideia do que seja a ciência nativa, o ideal é participar do mundo natural. Para entendermos os fundamentos da ciência nativa, devemos abrir-nos para as funções da sensação, da percepção, da imaginação, da emoção, dos símbolos e dos espíritos, assim como para as do conceito, da lógica e do empirismo racional.

Muito da essência da ciência indígena está além da descrição literal. Na verdade, palavras incorretas ou mal empregadas frequentemente destroem a real experiência holística da natureza enquanto ato de participação direta em torno do qual tais conhecimentos evoluíram. Nos termos literais da biologia, a ciência in dígena pode ser vista como uma exemplificação de "biofilia", ou o instinto inato de que todas as formas de vida compartilham entre si por afiliação. Em termos antropológicos, a ciência indígena tem sido vista como "animismo", "totemismo", ou adoração da natureza. Dentro da moldura conceptual da filosofia, poderíamos dizer que a ciência indígena se baseia na fenomenologia perceptual. Em essência, a ciência indígena se baseia na percepção adquirida do uso de todos os sentidos de nossos corpos em participação direta com o mundo natural.

O que é ciência indígena? Para responder a esta questão, é importante definir algumas fronteiras. Ciência indígena é um termo amplo que pode incluir metafísica e filosofia; arte e arquitetura; tecnologias práticas e agricultura; e rituais e cerimônias praticados por povos indígenas tanto no passado quanto no presente. Mais especificamente, ciência indígena engloba áreas tais como astronomia, lavoura, domesticação de plantas, plantas medicinais, criação de animais, caça, pesca, metalurgia e geologia - em suma, estudos relacionados a plantas, animais e fenômenos naturais. A ciência indígena abrange ainda a espiritualidade, comunidade, criatividade e tecnologias que sustentam ambientes e suportam aspectos essenciais da vida humana. Ela pode mesmo incluir a 
exploração de questões tais como a da natureza da linguagem, do pensamento e da percepção; o movimento do tempo e do espaço; a natureza do conhecimento e do sentimento humanos; a natureza do relacionamento humano com os cosmos; e todas as questões relativas à realidade natural. Ciência indígena é uma herança coletiva da experiência humana com o mundo natural; em sua forma mais essencial, é um mapa da realidade natural derivado da experiência de milhares de gerações humanas. Deu origem à diversidade de tecnologias humanas, mesmo ao advento da ciência mecanicista moderna. Indo mais fundo, podemos dizer que ciência indígena é "inclusiva" da ciência moderna, ainda que os cientistas ocidentais venham a negar tal inclusividade a todo custo.

Alguns modernos, tanto cientistas quanto não cientistas, argumentam que não há uma ciência indígena, que ciência é uma construção ou conceito essencialmente ocidental. $\mathrm{E}$ que embora os povos indígenas tenham modos e conhecimentos tradicionais, tais conhecimentos não são científicos. Esta argumentação afirma que a expressão "ciência indígena" é essencialmente sem sentido. Alguns buscam a ciência enquanto um modo de compreensão do mundo, como uma história de como as coisas acontecem, como um modo que os seres humanos desenvolveram para tentar entender e explicar a existência no tempo e no espaço e as relações vis-à-vis com os processos naturais do mundo. Nesta perspectiva, toda cultura tem ciência.

Outra questão importante que surge é o viés cultural. Alguns cientistas ocidentais insistem que a ciência deve ser objetiva para ser qualificada enquanto ciência, que é culturalmente neutra e de alguma forma existe fora da cultura e por isso não é afetada pela cultura. $O$ contra-argumento é que cientistas sociais em particular devem concordar que nada que as pessoas fazem é divorciado da cultura, incluindo sistemas de conhecimento, tecnologia e educação. Tudo é contextualizado na cultura. Há vário mitos dentro da própria ciência ocidental que estão sendo testados pelos cientistas ocidentais.

Ao falarmos sobre ciência indígena ou nativa, estamos falando na verdade de todo o edifício do conhecimento indígena. Usar a palavra "ciência" é muitas vezes arbitrário, e pode ser que se refira especificamente aos modos como as pessoas vêm a conhecer uma coisa ou outra. Mas a ciência indígena engloba todos os tipos de conhecimento que fazem parte de uma mentalidade indígena, que é essencialmente relacional. Desta forma, termos como "conhecimento" e "ciência" são usados alternadamente entre cientistas indígenas.

A ciência indígena é mais relacionada ao que a ciência ocidental chama de ciência ambiental ou ecologia. E se por um lado os povos nativos não têm uma palavra específica para 
nenhum destes termos ocidentais, eles certamente têm um entendimento prático destas disciplinas da ciência ocidental em nível individual e comunal. E portanto tal entendimento que os povos indígenas têm é fruto de um relacionamento bastante particular e profundo com o mundo natural. Este relacionamento é baseado no fato de que todas as tribos indígenas - suas filosofias, modos culturais de vida, costumes, línguas, todos os aspectos de seus seres culturais de um modo ou de outro - são fundamentalmente atadas às relações que elas estabeleceram e aplicaram, ao longo de sua história, a certos lugares e à terra como um todo.

Este livro busca prover uma lente diferente através da qual se possam ver a ciência e a tecnologia das tradições indígenas. Como é próprio de todas as lentes, o que se pode ver depende da claridade das imagens possibilitada pelo uso de uma lente em particular. Nos últimos quinhentos anos de contato com a cultura ocidental, as tradições indígenas têm sido vistas e expressas majoritariamente através de lentes do pensamento da linguagem e da percepção ocidental. As lentes ocidentais refletem todas as outras tradições culturais através de filtros de uma visão moderna do mundo. Para entender as culturas indígenas, deve-se ser capaz de ver através de suas lentes e ouvir suas histórias em suas vozes e através de suas experiências.

Uma lente culturalmente mediada baseada na "participação com a natureza" é a visão da qual a ciência indígena evoluiu.
Em meu foco sobre relacionamento e participação, eu tenho propositalmente revisto as "contribuições" indígenas ou apresentado comparações entre ciência ocidental e indígena apenas quando elas são necessárias para ilustrar a "psicologia" de participação na cosmologia, na filosofia e na relação com as plantas, animais e paisagens indígenas. A participação fornece o fundamento para o caminho da ciência indígena em todos os níveis e expressões. As dinâmicas desta participação são fundadas num pacto ancestral entre humanos e plantas, animais e forças da terra e do universo. É a profundidade de nossa comunhão humana ancestral com a natureza que tem sido perdida e precisa ser recuperada de forma substancial na vida e na ciência modernas. O cosmológico e o filosófico devem novamente se tornar "enraizados" em uma experiência do mundo natural centrada na vida.

Este trabalho é uma exploração do processo de participação criativa da ciência indígena que é aludido, mas raramente explicado, na apresentação usual das conquistas das tecnologias nativas. As tecnologias indígenas são o resultado de um entendimento muito sofisticado e multifacetado dos processos ecológicos. Este trabalho não buscará uma apresentação enciclopédica de exemplos da ciência e tecnologias indígenas, mas, antes, uma exploração em profundidade de expressões selecionadas do conhecimento nativo que ilustrem seu inerente processo criativo. 
Meu objetivo neste livro é prover um entendimento geral dos paradigmas da ciência indígena. Cada capítulo segue o formato geral do processo criativo, começando com os primeiros insights, seguido pela imersão nos pensamentos guiando um tema em particular da ciência indígena, seguido pela exemplificação da criação ou tecnologia criativa refletindo aquele tema, discussão de apresentação do processo criativo da ciência, e implicações da integração entre ciência e espírito.

O capítulo 1, "Contando uma história especial", metaforicamente apresenta o centro, a dinâmica interior onde todas as coisas começam e para onde retornam. Este capítulo é uma exploração da natureza participativa e holística do processo criativo e seus reflexos nas etnociências das culturas nativo-americanas. O objetivo deste capítulo é ajudar o leitor a desenvolver um fundamento básico do processo criativo enquanto refletido no mundo natural e no contexto da expressão cultural nativo-americana.

O capítulo 2, "Filosofia da ciência nativa", metaforicamente representa o leste, a orientação do sol nascente, do vento matinal e da primeira luz do dia. Explora a filosofia centrada na terra, "ordenando" paradigmas (padrões de pensamento) das Américas Indígenas do Norte, Central e do Sul. A ênfase estará nos modos como estes paradigmas de participação sensível, consciência ecológica e relacionamento têm guiado os pensamentos, valores, estéticas, éticas e ações das expressões nativo-americanas de ciência, formas de arte, símbolos, poesia oral, mitologia e literatura. Um foco especial é colocado sobre os componentes da ciência indígena, com vistas a aumentar o entendimento dos processos naturais do "vir a saber" em relação ao lugar e à comunidade.

O capítulo 3, "A ecologia da comunidade nativo-americana”, apresenta a orientação do oeste, o lugar do sol poente e do vento seco, que metaforicamente corresponde à continuidade ancestral e à função essencial da comunidade. Este capítulo foca a interdependência dos paradigmas social e ecológico e suas influências na psicologia cultural e na ecologia social das pessoas nativo-americanas, no passado e no presente.

O capítulo 4, "Plantas, comida, remédio e jardinagem", apresenta o orientação do sul, o lugar dos ventos curadores, que trazem a chuva e nutrem o solo. Este capítulo trata dos vários aspectos da herbologia e conceitos de saúde holística em tradições nativo-americanas que exemplificam relações com plantas, que são, por sua vez, regidas pela história, pelas aplicações práticas e por conceitos subjacentes de saúde e integridade. O capítulo se inicia com perspectivas indígenas tradicionais de plantas como alimentos e remédio e continua através de práticas e perspectivas de terapêutica de saúde holística contemporânea. 
O capítulo 5, "Animais no mito e na realidade indígena", metaforicamente representa o norte, o lugar dos animais e do vento forte, e apresenta uma investigação sobre a educação, a ecologia e a filosofia indígena/tribal, vistas de uma perspectiva da mitologia animal e da relação real com os animais. Enfatiza-se essa relação especial expressa na arte, na ciênci aplicada, e em experiências visionárias e na ética ambiental.

O capítulo 6, "Um sentido de lugar", metaforicamente representa o orientação do subterrâneo, ou da terra. Este capítulo explora a ética ecológica nativo-americana como expressa em pensamento e ação, visando os elementos primordiais do mundo físico e da própria terra. Tratará das relações e do entendimento ecológicos dessas forças elementares como reflexos do tecido cultural dos nativo-americanos. Áreas enfatizadas incluem linguagem, história, arte, arquitetura, filosofia e ciência aplicada.

O capítulo 7, "Astronomia nativa: uma visão celestial”, reflete a orientação do superior, o lugar das origens celestiais. Este capítulo explora as habilidades, técnicas, perspectivas culturais e cosmologias-guia que caracterizam a expressão indígena da astronomia. Enfatiza como os nativo-americanos têm representado criativamente seu senso de relação e ressonância com o céu. A intenção é criar um entendimento básico das influências que a observação de estrelas e planetas, da lua e do sol e de outros fenômenos celestiais tem tido na percepção cultural do passado e do presente nativo-americano.

O capítulo 8, "Criando novas mentes e mundos", apresenta pensamentos finais sobre o significado da ciência indígena no intuito de forjar uma nova visão da ciência ocidental que incluiria a consciência ecológica e as relações recíprocas mútuas presentes na fundação da ciência indígena em sua prática e expressão diárias. Este capítulo conecta as perspectivas presentes na ciência indígena ao pensamento e à ação que podem ser assumidas hoje e amanhã para ocasionar o "novo sol" de um futuro mais esperançoso e alegre para a terra e consequentemente para a humanidade.

Minha esperança com este livro é que ele forneça aos indígenas um material cuidadoso de princípios-chave e entendimentos da ciência indígena para servir como fundamentos para diálogos e discussões. Para aqueles devotados à cultura e às ciência ocidentais, eu espero que o livro proveja insights mais profundos e uma apreciação da sabedoria da ciência indígena. O que todos precisamos neste momento é uma ponte que beneficie mutuamente e crie um diálogo entre as comunidades científicas ocidental e indígena. Este livro e outros trabalhos do mesmo gênero constituem um primeiro passo.

Quanto mais a ciência indígena se torne amplamente conhecida em termos de diálogo e discussão, maiores serão os 
desafios aos fundamentos básicos da epistemologia e da ontologia científica ocidental. Nestes círculos de debate, cientistas como F. David Peat e Fred Alan Wolf, bem como muitos estudiosos indígenas, estão discutindo ciência de um modo que seja proveitoso para a troca de conhecimentos. Entre os próprios índios, a ciência indígena se tornou um slogan de união para muitas coisas, tal como um esforço para começar uma revitalização e uma disseminação de suas próprias bases de conhecimento. Tem a ver com o fortalecimento de ideias básicas com vistas a inseri-las na cultura moderna.

O que é problemático desde a perspectiva dos povos indígenas é o fato de que eles se tornaram muito desconfiados das premissas e motivos que subjazem à ciência ocidental no que se refere ao significado das histórias, cerimônias, rituais e tudo mais que representa ideias e princípios centrais. Indivíduos indígenas se tornaram mais cautelosos que nunca por causa da apropriação de suas ideias e conceitos culturais. Esta preocupação em relação à apropriação se estende a plantas que são retiradas da Floresta Amazônica e patenteadas por companhias farmacêuticas, sem compensações efetivas às nações nativas da região que proveram as informações sobre a utilidade das plantas e que têm vivido naquele ecossistema por séculos ou milênios.

Conhecimento e informação se tornaram commodities. Nações indígenas têm experimentado a expropriação de suas terras e seu trabalho. Neste estágio da história, estes povos têm se sensibilizado quanto ao fato de terem seu conhecimento apropriado num contexto em que o entendimento, $\mathrm{e}$ muito menos a viabilidade concreta, de uma reciprocidade não existe. Consequentemente, o controle e o acesso à informação são questões que se colocam para os povos indígenas. Pode-se dizer que um campo de ação mais igualitário é essencial para a troca de informação entre os praticantes da ciência ocidental e indígena.

Algumas tribos certamente são mais precavidas que outras em compartilhar informação. Os Huichol do México são uma das tribos que têm sido menos desconfiadas por razões próprias (ainda que eles também possam estar em fase de reconsiderar seus modos, digamos, liberais). Eles se tornaram uma espécie de ícone para alguns grupos New Age que expuseram as tradições Huichol para o resto do mundo. Enquanto isso, os Huichol continuam engajados numa longa batalha por direitos básicos, como o controle de suas terras, recursos, sistema educacional e comunidades. Como outros povos indígenas, os Huichol buscam igualdade social e o direito de manter seu modo de vida tradicional.

Dada essa situação, povos indígenas têm se utilizado de várias estratégias: uma delas é sonegar informação. Seja como for, esta é uma faca de dois gumes no que tange ao fato de que muitos anciãos, que têm conhecimentos específicos 
de processos naturais e de ecossistemas, morrem sem transmitir a informação a outros. Assim, esta informação intrincada e harmoniosamente organizada é perdida. Claro que há também a hipótese, como querem alguns filósofos, indígenas ou não, de que o conhecimento nunca é realmente perdido; ele surge quando é necessário, e desaparece quando não é mais útil.

Talvez a vantagem para os povos indígenas aconteça em termos de um maior entendimento por parte dos ocidentais da profunda sabedoria contida na ciência indígena, maior notoriedade para os povos indígenas, e maior respeito por parte do público em geral em relação ao modo de vida, aos direitos e às questões indígenas. Todavia, sérios problemas continuam em termos de abuso, exploração e equívocos perpetrados por corporações, governos e outras entidades. Esperamos que o mais cedo possível a sociedade ocidental entenda que os povos nativos não são simples vestígios do passado e fontes de ideias bonitas e interessantes, mas que eles estão bastante vivos hoje em dia, e que suas questões políticas e econômicas devem ser tratadas em seus próprios termos. 